\title{
Role of Brain and Peripheral Angiotensin II in Hypertension and Altered Arterial Baroreflex Programmed during Fetal Life in Rat
}

\author{
PATRICK PLADYS, ISABELLE LAHAIE, GILLES CAMBONIE, GAÉTAN THIBAULT, \\ NGOC LOAN OANH LÊ, DANIEL ABRAN, AND ANNE MONIQUE NUYT \\ Centre de Recherche de l'Hôpital Sainte-Justine [P.P., G.C., I.L., N.L.O.L., D.A., A.M.N], Department of \\ Pediatrics, Université de Montréal, Montréal, Québec, Canada, H3T 1C5; and Institut de recherches cliniques \\ de Montréal [G.T.], Montréal, Québec, Canada, H2W 1R7. P.P. current address: Unité de médecine néonatale, \\ Hôpital Sud, CHU Rennes, 16 Bd de Bulgarie, BP 90347, 35203 Rennes Cedex 2, France
}

\begin{abstract}
Intrauterine programming of hypertension is associated with evidence of increased renin-angiotensin system (RAS) activity. The current study was undertaken to investigate whether arterial baroreflex and blood pressure variability are altered in a model of in utero programming of hypertension secondary to isocaloric protein deprivation and whether activation of the RAS plays a role in this alteration. Pregnant Wistar rats were fed a normalprotein $(18 \%)$ or low-protein $(9 \%)$ diet during gestation, which had no effect on litter size, birth weight, or pup survival. Mean arterial blood pressure (MABP; $126 \pm 3 \mathrm{~mm} \mathrm{Hg} \mathrm{9 \%} \mathrm{versus} 108$ $\pm 4 \mathrm{~mm} \mathrm{Hg} 18 \% ; p<0.05)$ and blood pressure variability were significantly greater in the adult offspring of the $9 \%$ protein-fed mothers. Arterial baroreflex control of heart rate, generated by graded i.v. infusion of phenylephrine and nitroprusside, was significantly shifted toward higher pressure; i.v. angiotensinconverting enzyme inhibitor normalized MABP and shifted the arterial baroreflex curve of the $9 \%$ offspring toward lower pressure without affecting the $18 \%$ offspring. For examining whether brain RAS is also involved in programming of hypertension, angiotensin-converting enzyme inhibitor and losartan (specific $\mathrm{AT}_{1}$ receptor antagonist) were administered intracerebroventricularly; both significantly reduced MABP of the $9 \%$ but not
\end{abstract}

\section{ABSTRACT}

the $18 \%$ offspring. Autoradiographic receptor binding studies demonstrated an increase in brain $\mathrm{AT}_{1}$ expression in the subfornical organ and the vascular organ of the lamina terminalis in the $9 \%$ offspring. These data demonstrate a major tonic role of brain and peripheral RAS on hypertension associated with antenatal nutrient deprivation. (Pediatr Res 55: 1042-1049, 2004)

$\quad$ Abbreviations
ACE-I, angiotensin-converting enzyme inhibitor
AngII, angiotensin II
AP, area postrema
BPV, blood pressure variability
HR, heart rate
ICV, intracerebroventricular
MABP, mean arterial blood pressure
MEPO, median preoptic nucleus
NTS, nucleus of the solitary tract
OVLT, vascular organ of the lamina terminalis
PVH, paraventricular nucleus of the hypothalamus
RAS, renin-angiotensin system
SFO, subfornical organ

Chronic cardiovascular diseases of adults can have their origins in fetal life. Epidemiologic studies reveal that hypertension, stroke, and coronary heart disease are inversely related

Received May 28, 2003; accepted February 11, 2004.

Correspondence: Anne Monique Nuyt, M.D., Research Center, Hôpital Sainte-Justine, Department of Pediatrics, University of Montreal, 3175 Côte Sainte-Catherine, Montreal, Quebec, Canada, H3T 1C5; e-mail: anuyt@justine.umontreal.ca

This work was supported by grants from the Canadian Institutes of Health Research and the Banting Research Foundation with matching funds from the Medical Research Council of Canada. P.P. was supported by a Institut National de Santé et Recherche Médicale (France) and the Canadian Institutes of Health Research (INSERM-CIHR) research fellowship and by the Conseil Régional de Bretagne.

A.M.N. is a recipient of a fellowship from the Fonds de la Recherche en Santé du Québec.

DOI: 10.1203/01.PDR.0000127012.37315.36 to birth weight (1) and that this relationship is independent of genetic factors (2) and lifestyle (3). It has been suggested that a poor nutrient supply at a critical period of early development leads to permanent alterations in the programming of the developing cardiovascular structures or functions (4). This concept has been supported by animal studies demonstrating an association between nutritional deficit during fetal life and increased blood pressure in adulthood $(5,6)$.

Experimental evidence suggests that activation of the reninangiotensin system (RAS) $(7,8)$ is an important element of hypertension programmed during fetal life. Infants who are born with intrauterine growth restriction have increased plasma renin activity and renal renin content $(9,10)$. In an animal 
model of in utero programming of hypertension, increased levels of pulmonary and plasma angiotensin converting enzyme (ACE) were found, whereas ACE inhibition (ACE-I) has been shown to normalize blood pressure $(7,8)$. Angiotensin II (AngII) can increase blood pressure and alter the arterial baroreflex through peripheral (vascular and renal) and central effects. Arterial baroreflex control of heart rate (HR) normally allows tight maintenance of blood pressure around a set point and has a key role in buffering blood pressure variability (BPV). There is indirect evidence suggesting abnormal control of HR in chronically growth impaired fetuses and in hypertensive adults who were nutrient deprived during fetal life (1113). Whether arterial baroreflex and BPV are impaired and whether peripheral and/or brain RAS could participate in hypertension and resetting of arterial baroreflex are unknown.

The current study was undertaken to test the hypothesis that in utero programmed hypertension is associated with an alteration of the arterial regulation (baroreflex and BPV) secondary to excess activation of the RAS. For this purpose, we used an animal model in which mildly restricting the protein intake of pregnant rats leads to hypertensive offspring (7). The first series of experiments were designed to explore whether arterial baroreflex control of HR was altered in this model and whether this alteration depended on endogenous AngII. The second series of experiments were developed to examine more specifically the role of endogenous central AngII and the AngII receptor subtype $\mathrm{AT}_{1}$ on arterial pressure; the $\mathrm{AT}_{1}$ receptor subtype mediates most, if not all, of the central cardiovascular effects of AngII $(14,15)$. Last, the expression of $\mathrm{AT}_{1}$ in the brain was studied using autoradiography. Our results reveal a role for both brain and peripheral RAS in maintaining elevated blood pressure in hypertension programmed during early life.

\section{METHODS}

\section{Animals}

Animals were used according to a protocol approved by the Animal Care Committee of the Hôpital Sainte-Justine in accordance with the principles of the Guide for the Care and Use of Experimental Animals of the Canadian Council on Animal Care. Virgin Wistar rats (initial weight 225-250 g) were mated overnight and on the day of conception (determined by the presence of a vaginal plug) were allocated to feed ad libidum on a diet containing either $18 \%$ (control) or $9 \%$ (low) protein (casein) diet $(5,7)$. All diets contained $5 \mathrm{~g} / \mathrm{kg}$ methionine to avoid sulfur deficiency and were made isocaloric with starch and sucrose supplement. Dams were weighed weekly. Within $12 \mathrm{~h}$ of delivery, the dams were returned to regular rat diet. Pups were weaned at $4 \mathrm{wk}$ of age to regular rat diet.

\section{Surgical Preparation}

Male offspring (9-12 wk old) were anesthetized with intraperitoneal ketamine $(65 \mathrm{mg} / \mathrm{kg})$ and xylazine $(7 \mathrm{mg} / \mathrm{kg})$. Under sterile conditions, polyethylene catheters (PE50; Plastics One, Roanoke, VA, U.S.A.) were inserted into a femoral artery and vein, tunneled subcutaneously to the back of the neck, threaded through a flexible metal spring, and connected to a dual- channel swivel mounted directly above the cage (Lomir Biomedical, Notre-Dame-de-L'Ile-Perrot, QC, Canada). This set-up allowed the rat freedom of movement within the cage.

In a second group of animals, an intracerebroventricular (ICV) cannula was implanted in addition to the femoral catheters. The anesthetized rat was placed in a stereotaxic apparatus (Kopf Instruments, Tujunga, CA, U.S.A.), and a 26-gauge stainless steel guide cannula was implanted immediately above the roof of the right lateral ventricle (stereotaxic coordinates with respect to bregma: $1 \mathrm{~mm}$ caudal and $1.5 \mathrm{~mm}$ lateral) and lowered $4 \mathrm{~mm}$ below the surface of the skull (16). The guide cannula was anchored to the skull with acrylic dental cement and sealed with a dummy cannula (Plastics One). Drugs were injected by inserting a 33-gauge stainless steel internal cannula into the guide cannula, which was connected to a $10-\mu \mathrm{L}$ Hamilton syringe. The correct ICV placement of the cannula was verified by post mortem injection of $5 \mu \mathrm{L}$ of black ink and examination of cryostat brain sections. At the end of the surgical procedures, each rat was given a dose of i.v. Cefazolin $(25 \mathrm{mg} / \mathrm{kg})$ and allowed to recover for $24 \mathrm{~h}$ before the experiment. To verify that this delay after surgery did not have an impact on the results obtained, four $9 \%$ and three $18 \%$ additional animals were studied $4 \mathrm{~d}$ after surgery; as the results obtained are similar, only the rats that were studied $24 \mathrm{~h}$ after surgery are presented.

\section{Experimental Procedures}

On the day of the experiment, the rats were brought in their cage to the laboratory and allowed to adapt for $30 \mathrm{~min}$. During each experiment, arterial blood pressure and HR were monitored continuously using a pressure transducer (The Perceptor, Namic, Glen Falls, NY, U.S.A.) aligned to the level of the heart, and a Grass recorder (Astro-Med, Grass, RI, U.S.A.) displayed and recorded on-line to a computer via a Grass PVA-1A 8-channel analog-to-digital conversion board using the software Polyview (version 2.3; Astro-Med).

In the first series of studies, baseline mean arterial blood pressure (MABP) and HR were recorded for $15 \mathrm{~min}$. Baroreflex curves were then determined by producing ramp changes in MABP with continuous i.v. infusion of phenylephrine (5-80 $\left.\mu \mathrm{g} \cdot \mathrm{kg}^{-1} \cdot \mathrm{min}^{-1}\right)$ or nitroprusside $\left(5-80 \mu \mathrm{g} \cdot \mathrm{kg}^{-1} \cdot \mathrm{min}^{-1}\right)$ over a 10-min period, using a Harvard infusion pump. A 30-min recovery period was allowed before the alternative drug was administered. The same protocol was repeated 90 min later, $20 \mathrm{~min}$ after i.v. ACE-I enalaprilat $(150 \mu \mathrm{g} / \mathrm{kg})$.

The second series of experiments were designed to evaluate the role of endogenous brain AngII on maintaining elevated blood pressure. Resting values for MABP and HR were obtained before and $20 \mathrm{~min}$ after ICV enalaprilat [ $20 \mu \mathrm{g} / \mathrm{kg}$ in 10 $\mu \mathrm{L}$ of saline ( $\mathrm{pH}$ 7.4)]. In the third series of experiments, the role of brain AngII $\mathrm{AT}_{1}$ receptors on resting MABP, HR, and resetting of arterial baroreflex control of HR was evaluated. For this purpose, baseline recordings and baroreflex curves were generated as described for the first series of experiments, before and after ICV injection of losartan [specific $\mathrm{AT}_{1}$ receptor antagonist, $30 \mu \mathrm{g} / \mathrm{kg}$ in $10 \mu \mathrm{L}$ of saline (pH 7.4)]. 


\section{Autoradiographic Expression of AngII-AT Receptor in $_{1}$ the Brain}

Consecutive coronal brain sections $(20 \mu \mathrm{m})$ from $18 \%$ and $9 \%$ 9- to 12 -wk-old male offspring were cut on a cryostat (Microm Cryostat, Waldorf, Germany) at $-25^{\circ} \mathrm{C}$ and thawmounted on microscope slides (Superfrost; VWR Scientific, Ville Mont-Royal, QC, Canada). Sections were preincubated for $15 \mathrm{~min}$ at room temperature with binding buffer $[10 \mathrm{mM}$ phosphate buffer ( $\mathrm{pH} 7.4$ ), $150 \mathrm{mM} \mathrm{NaCl}, 5 \mathrm{mM} \mathrm{Na}_{2}$ EDTA, $0.4 \mathrm{mM}$ bacitracin, $0.2 \% \mathrm{BSA}$ ], then for $1 \mathrm{~h}$ in the same buffer containing $2.5 \times 10^{-10} \mathrm{M}^{125} \mathrm{I}_{-}\left[\mathrm{Sar}^{1}\right.$, $\left.\mathrm{Ile}^{8}\right]$ AngII with 2.103 $\mathrm{Ci} / \mathrm{mmol}$ (Amersham) with or without $10^{-6} \mathrm{M}$ losartan. Nonspecific binding was determined in the presence of $10^{-6} \mathrm{M}$ unlabeled $\left[\mathrm{Sar}^{1}, \mathrm{Ile}^{8}\right.$ ]AngII. Subsequently, the tissue sections were transferred through four 1-min washes in $4^{\circ} \mathrm{C}$ incubation buffer without BSA, dipped in $4^{\circ} \mathrm{C}$ deionized water, and rapidly dried under a stream of cold air. Slides were exposed to Kodak Biomax MS films for $6 \mathrm{~d}$ at $-80^{\circ} \mathrm{C}$.

\section{Data Analysis}

$\boldsymbol{B P V}$. Three-minute periods were extracted from baseline recordings when the quality of the arterial blood pressure signal was visually considered to be satisfactory (steady MABP, no agitation, no dampening, and no artifacts). Before spectral analysis, a least-squares linear procedure was used to remove any linear offset and trend from the data. Spectral analysis of the data was performed using the Fast Fourier Transform algorithm with a Hamming window (Polyview 2.3, Astro-Med). The total power spectral density (variance), which is an index of global variability, was calculated by integrating the power spectra over the frequency range $(0.1-2.5 \mathrm{~Hz})$ and expressed in $\mathrm{mm} \mathrm{Hg}^{2}$. The spectral densities in the very low frequency range $(0.1-0.2 \mathrm{~Hz})$, in the low frequency range $(0.2$ to $0.7 \mathrm{~Hz})$, and in the high frequency range $(0.7-2.5 \mathrm{~Hz})$ were also calculated (17). The frequency variations of $<0.1 \mathrm{~Hz}$ were not considered to avoid possible artifacts as a result of longterm slow oscillations. Normalization procedure was performed by dividing the power of low frequency and high frequency by the total power spectral density and by multiplying the result by 100 .

Arterial baroreflex control of heart rate. The HR response to changes in MABP was used to generate the baroreflex curve. The different baroreflex curves, expressed as the relationship between MABP and HR, were analyzed with a logistic sigmoid function (Graph Pad Inplot version 4.03; GraphPad Software, San Diego, CA, U.S.A.) according to the following equation: $\mathrm{HR}=\mathrm{P}_{4}+\mathrm{P}_{1} /\left\{1+\exp \left[\mathrm{P}_{2}\left(\mathrm{MABP}-\mathrm{P}_{3}\right)\right]\right.$, where $\mathrm{P}_{1}$ is the range between the upper and lower plateaus, $\mathrm{P}_{2}$ is a coefficient used to calculate the gain as a function of pressure, $\mathrm{P}_{3}$ is the MABP at midrange of the curve, and $\mathrm{P}_{4}$ is the lower plateau (18). The gain (slope) was calculated from the first derivative of the above equation. Threshold pressure (lowest pressure that produces a significant decline in HR) and saturation pressure (pressure necessary to achieve maximal inhibition of HR) were calculated from the third derivative of the equation (18).

Quantitative ex vivo receptor autoradiography. Total ${ }^{125} \mathrm{I}$ $\left[\mathrm{Sar}^{1}, \mathrm{Ile}^{8}\right]$ AngII receptor binding and radioligand binding in the presence of losartan were quantified in the brain areas that are involved in cardiovascular regulation and that expressed $\mathrm{AT}_{1}$ binding sites (14). For quantifying receptor-ligand binding in the examined brain regions, calibrated OD measurements (transmitted light) of digitized autoradiograms were carried out after normalizing for background tone. Losartan-sensitive binding was used to estimate $\mathrm{AT}_{1}$ binding and was obtained by subtracting binding in the presence of losartan from total binding (ImagePro software; Media Cybernetics, San Diego, CA, U.S.A.). In each experiment (i.e. radiographic film), the binding densities were obtained for one $9 \%$ and one $18 \%$ brain. Seven brains from each group of rats were studied, with a median of 110 sections per brain. The maximum $\mathrm{AT}_{1}$ binding densities within each brain structure were calculated and expressed as a percentage of the $\mathrm{AT}_{1}$ binding in the corresponding control brain region (set as 100\%) and in fmol/mg protein using calibrated autoradiographic ${ }^{125} \mathrm{I}$ microscale (Amersham, Baie D'Urfé, QC, Canada).

\section{Chemicals}

The following agents were purchased: sodium nitroprussiate, phosphate buffer, EDTA, AngII, and BSA (Sigma Chemical Co., St. Louis, MO, U.S.A.); bacitracin and (3$\left[{ }^{125} \mathrm{I}\right]$ iodotyrosyl ${ }^{4} \mathrm{Sar}^{1} \mathrm{Ile}^{8}$ AngII $\left({ }^{125} \mathrm{I}-\left[\mathrm{Sar}^{1}, \mathrm{Ile}^{8}\right]\right.$ AngII; Amersham Biosciences); enalaprilat (Vasotec; Merck Frosst, Kirkland, QC, Canada); Ketamine (Ayerst, Montreal, QC, Canada); Xylazine (Bayer, Etobicoke, Ont, Canada); and Cefazolin (Novopharm, Scarborough, Ont, Canada). Losartan was a gift of Merck Frosst Canada and Du Pont (Kirkland, QC, Canada).

\section{Statistical Analysis}

All results are expressed as mean \pm SEM. Analysis of differences within and between groups was performed using multivariate ANOVA, $t$ test for paired or unpaired observations, and Wilcoxon or Mann-Whitney tests as appropriate. A simple linear regression analysis was used to determine the correlation between BPV parameters and MABP. Statistical significance was set at $p<0.05$.

\section{RESULTS}

Net weight gain during pregnancy of dams fed the lowprotein $(9 \%)$ and control $(18 \%)$ diets was similar $(9 \% 144 \pm$ $7 \mathrm{~g}, n=18 ; 18 \% 142 \pm 5 \mathrm{~g}, n=19)$. Dietary protein affected neither the litter size $(9 \% 14.9 \pm 0.9, n=7 ; 18 \% 14.8 \pm 0.7$, $n=8$ ) nor the survival rate of the offspring during the 12 -wk study period. Birth weight did not differ between groups $(9 \%$ $5.3 \pm 0.1 \mathrm{~g}, n=14 ; 18 \% 5.6 \pm 0.2 \mathrm{~g}, n=14$ ).

Effects of systemic ACE-I on baseline HR, MABP, BPV, and arterial baroreflex. The baseline MABP was significantly higher in the $9 \%$ offspring (Fig. 1A), whereas HR was similar (see operating point in Table 1). The BPV, measured by total power spectral density, was also higher in the $9 \%$ offspring; this increase was observed in both low- and high-frequency bands (Table 2, Fig. 2).

I.v. enalaprilat significantly reduced MABP of the $9 \%$ offspring rats without changing HR; baseline MABP and HR were 

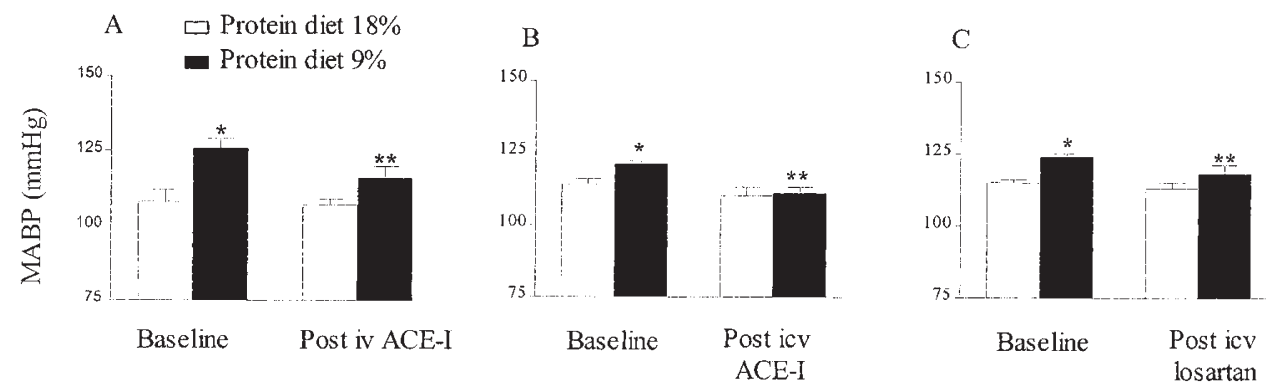

Figure 1. Effects of maternal diets that contain $18 \%$ (control; $\square$ ) and $9 \%$ (low; $\square$ ) protein on MABP of the 9- to 12-wk-old offspring in three sets of experiments: before (baseline) and after i.v. administration of ACE-I enalaprilat ( $n=7$ for each group; $A$ ) before (baseline after ICV) and after ICV administration of enalaprilat $(n=3$ for each group; $B)$, and before and after ICV losartan (AngII $\mathrm{AT}_{1}$ receptor antagonist, $n=5$ for each group; $C$ ). Data are means \pm SEM. $* p<0.05$ vs $18 \%$ baseline; $* * p<0.05$ vs $9 \%$ baseline.

Table 1. Parameter values describing arterial baroreflex control of HR before (baseline), after i.v. administration of ACE-I enalaprilat, and after ICV administration of AngII AT 1 receptor antagonist losartan in 9- to 12-wk-old rats exposed during gestation to a low protein (9\%) or control (18\%) diet

\begin{tabular}{|c|c|c|c|c|c|}
\hline & \multicolumn{2}{|c|}{ Control $(18 \% ; n=6)$} & \multicolumn{3}{|c|}{ Low-protein diet $(9 \% ; n=6,5$ for ICV losartan) } \\
\hline & Baseline & i.v. ACE-I & Baseline & i.v. ACE-I & ICV losartan \\
\hline \multicolumn{6}{|l|}{ HR } \\
\hline Lower plateau [bpm (\%)] & $\begin{array}{l}302 \pm 16 \\
(65 \pm 3)\end{array}$ & $\begin{array}{c}293 \pm 20 \\
(64 \pm 4)\end{array}$ & $\begin{array}{l}273 \pm 23 \\
(56 \pm 4)\end{array}$ & $\begin{array}{l}303 \pm 16 \\
(63 \pm 3)\end{array}$ & $\begin{array}{c}287 \pm 11 \\
(59 \pm 2)\end{array}$ \\
\hline Range (bpm) & $167 \pm 23$ & $170 \pm 25$ & $226 \pm 33$ & $173 \pm 10$ & $175 \pm 18$ \\
\hline Gain $[\mathrm{bpm} / \mathrm{mm} \mathrm{Hg}(\%) / \mathrm{mm} \mathrm{Hg}]$ & $\begin{array}{c}-4.3 \pm 0.9 \\
(-0.92 \pm 0.16)\end{array}$ & $\begin{array}{c}-3.9 \pm 0.6 \\
(-0.83 \pm 0.11)\end{array}$ & $\begin{array}{c}-4.4 \pm 0.5 \\
(-0.9 \pm 0.12)\end{array}$ & $\begin{array}{c}-4.2 \pm 0.3 \\
(-0.86 \pm 0.1)\end{array}$ & $\begin{array}{c}-4.7 \pm 0.4 \\
(-0.97 \pm 0.08)\end{array}$ \\
\hline Operating point $[\mathrm{bpm}(\%)]$ & $\begin{array}{l}353 \pm 22 \\
(75 \pm 5)\end{array}$ & $\begin{array}{l}375 \pm 26 \\
(80 \pm 6)\end{array}$ & $\begin{array}{l}362 \pm 12 \\
(74 \pm 2)\end{array}$ & $\begin{array}{l}361 \pm 17 \\
(74 \pm 3)\end{array}$ & $\begin{array}{l}361 \pm 19 \\
(74 \pm 4)\end{array}$ \\
\hline \multicolumn{6}{|l|}{ MABP } \\
\hline
\end{tabular}

Values are mean \pm SEM. Values of HR are expressed in beats per minute (and as \% of maximal HR achieved during infusion of nitroprusside for each rat under control conditions). Operating point corresponds to the baseline values of HR and MABP in resting conditions.

$* p<0.05$ vs $18 \%$ baseline.

$\dagger p<0.05$ vs $9 \%$ baseline.

$\ddagger p<0.05$ vs $18 \%$ post ACE-I.

unaffected in the $18 \%$ control animals (Fig. 1A, Table 1). Enalaprilat partially normalized BPV of the $9 \%$ group as it abolished the statistically significant difference observed between the groups in baseline conditions $(9 \%$ post-ACE-I not significantly different from $18 \%$ baseline and post-ACE-I values), although the $9 \%$ post-ACE-I BPV values remained not significantly different from baseline (Table 2). The BPV parameters were not correlated with resting MABP either before or after enalaprilat. HR baroreflex response curve threshold, saturation, and midpoint pressures of the $9 \%$ offspring were elevated, indicating a significant shift of the baroreflex toward higher pressures; i.v. enalaprilat reset the arterial baroreflex curve of $9 \%$ toward lower pressure without modifying the baroreflex curve of the $18 \%$ offspring (Table 1, Fig. 3).

Effects of brain AngII on baseline MABP and on arterial baroreflex. ICV enalaprilat, as well as losartan, significantly reduced the MABP of the $9 \%$ offspring without changing the resting MABP of the $18 \%$ control group (Fig. $1 B$ and $C$ ). When compared with baseline, ICV losartan did not significantly change the baroreflex curve of the $9 \%$ offspring despite a tendency to shift the curve toward lower pressure (Table 1).

Effects of low-protein diet on brain $A T_{1}$ receptor expression. Considering the effects of inhibiting brain AngII on MABP of the $9 \%$ but not the $18 \%$ offspring, we sought to determine whether brain $\mathrm{AT}_{1}$ receptor expression was increased in the $9 \%$ offspring. Nonspecific binding determined with an excess of unlabeled AngII was negligible $(<5 \%$ of total binding). Because we used a single subsaturating concentration of ${ }^{125} \mathrm{I}-\left[\mathrm{Sar}^{1}, \mathrm{Ile}^{8}\right]$ AngII, the binding results presented below may reflect the affinity as well as the quantity of receptors. Autoradiographic analysis of the brain sections from both groups revealed specific AngII $\mathrm{AT}_{1}$ receptor binding localized in the vascular organ of the lamina terminalis (OVLT), median preoptic nucleus (MEPO), subfornical organ (SFO), paraventricular nucleus of the hypothalamus (PVH), nucleus of the solitary tract (NTS), dorsal motor nucleus of the 
Table 2. Spectral measurements of arterial BPV in 9- to 12-wk-old rats exposed during gestation to a low-protein (9\%) or control (18\%) diet

\begin{tabular}{|c|c|c|c|c|}
\hline & \multicolumn{2}{|c|}{ Control $(18 \% ; n=6)$} & \multicolumn{2}{|c|}{ Low-protein diet $(9 \% ; n=8)$} \\
\hline & Baseline & Post ACE-I & Baseline & Post ACE-I \\
\hline Variance $\left(\mathrm{mm} \mathrm{Hg}^{2}\right)$ & $38 \pm 6$ & $48 \pm 12$ & $63 \pm 10^{*}$ & $54 \pm 8$ \\
\hline Low frequency $\left(\mathrm{mm} \mathrm{Hg}^{2}\right)$ & $17 \pm 3$ & $21 \pm 4$ & $26 \pm 5^{*}$ & $23 \pm 5$ \\
\hline High frequency $\left(\mathrm{mm} \mathrm{Hg}^{2}\right)$ & $14 \pm 3$ & $19 \pm 5$ & $28 \pm 5^{*}$ & $23 \pm 4$ \\
\hline LFnu (\%) & $45 \pm 2$ & $47 \pm 2$ & $40 \pm 6$ & $42 \pm 4$ \\
\hline HFnu $(\%)$ & $37 \pm 2$ & $40 \pm 4$ & $43 \pm 6$ & $43 \pm 4$ \\
\hline
\end{tabular}

Values are mean \pm SEM. $9 \%$ post ACE-I values were not statistically different from $9 \%$ baseline, $18 \%$ baseline, and $18 \%$ post ACE-I. LFnu and HFnu, normalized low and high frequency power, i.e. expressed as percent of total power spectral density (see "Methods").

$* p<0.05$ vs $18 \%$ baseline.
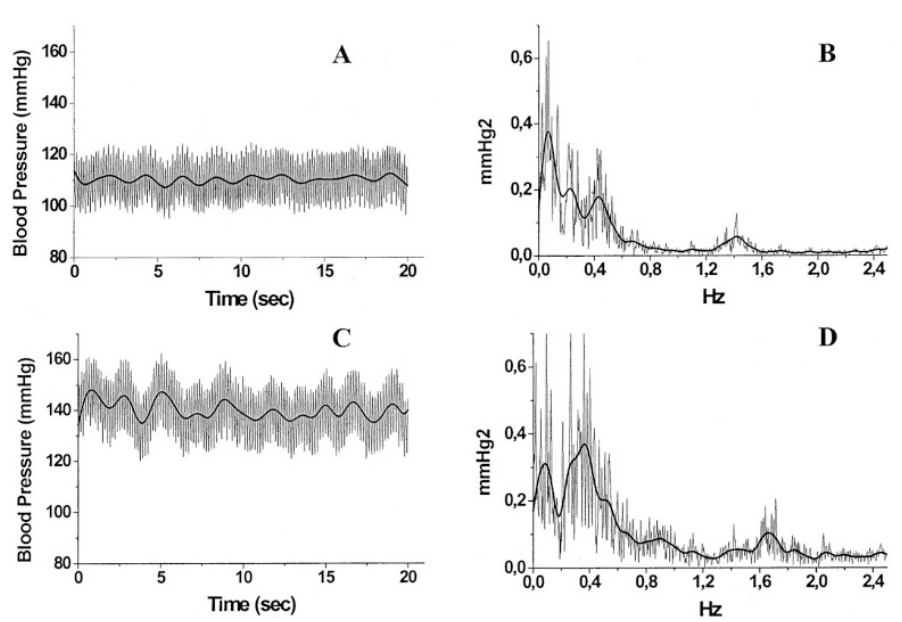

Figure 2. Representative tracing of the increase in BPV in the low-proteinexposed offspring group $(9 \% ; C$ and $D)$ when compared with the control group $(18 \% ; A$ and $B)$. ( $A$ and $C$ ) The blood pressure traces (20-s samples, in gray) are presented together with the evolution of the MABP (low-pass filter, in black). (B and D) Results of the spectral analysis (3-min periods). The higher BPV in the $9 \%$ group involves an increase in spectral density in both low-frequency $(0.2-0.7 \mathrm{~Hz})$ and high-frequency $(0.7-2.5 \mathrm{~Hz})$ ranges (see Table 1).

vagus, and area postrema (AP). In all of these areas, losartan displaced ${ }^{125} \mathrm{I}-\left[\mathrm{Sar}^{1}, \mathrm{Ile}^{8}\right]$ AngII binding. The binding analysis did not include the AP, which was not visible in all of the experiments, or the dorsal motor nucleus of the vagus, which was difficult to define from the NTS. All other brain regions demonstrated a higher binding density in the $9 \%$ offspring, and the difference reached statistical significance in the OVLT (116 $\pm 30 \%)$ and in the SFO (100 $\pm 38 \%$; Fig. 4$)$.

\section{DISCUSSION}

Epidemiologic studies indicate that antenatal nutrient depletion is associated with hypertension and increased risk of cardiovascular-related morbidity and mortality in adult life (4, 19-22). We have reproduced a rat model of hypertension, induced during early life through isocaloric $50 \%$ protein restriction of pregnant dams. The diet provides $75 \%$ of the basic protein required during gestation $(5,7)$ and is not associated with significant intrauterine growth restriction (23). Our results confirm that peripheral blockade of AngII decreases blood pressure of low-protein-diet-exposed offspring and demonstrate that in utero programmed hypertension is associated with increased spontaneous BPV and impaired arterial baroreflex control of HR. In addition, the decrease in blood pressure induced by central blockade of AngII $\mathrm{AT}_{1}$ receptor, as well as the increase in $\mathrm{AT}_{1}$ receptor expression in brain cardiovascular regulating areas of the $9 \%$ offspring, indicates an important role for the brain RAS. Taken together, these data demonstrate a major tonic role of both peripheral and brain RAS in maintaining in utero programmed chronic hypertension.

$\boldsymbol{B P V}$. Spontaneous BPV of the $9 \%$ offspring is increased in both high- and low-frequency ranges, which indicates impaired blood pressure regulation. It is interesting that it was recently shown that children with lower birth weight tend to have higher BPV independent of their blood pressure (24). Whereas hypertension is a primary cardiovascular risk factor, fluctuations in arterial blood pressure may also be of considerable importance and has been shown, independent of blood pressure, to lead to end organ damage classically associated with hypertension (25). The most intensively studied and probably most effective mechanism to maintain arterial blood pressure within narrow boundaries is the arterial baroreceptor reflex. The mechanisms involved in this increased BPV could comprise, at least for the low-frequency oscillations, a change in arterial baroreflex, which we also demonstrate in this series of studies. Activation of RAS has been proposed as a mechanism that contributes to end organ damage induced by increased BPV (25). However, considering that blockade of endogenous AngII formation significantly reset arterial baroreflex control of HR toward values comparable to control animals but did not completely normalize BPV, other factors are likely implicated in this increased BPV. Nitric oxide participates in the buffering of blood pressure variations $(17,26)$, and a defect in nitric oxide-mediated effects, which we recently demonstrated in brain microvessels of $9 \%$ offspring (27), could lead to increased BPV. Reduced arterial distensibility, as reported in those who are born with intrauterine growth restriction (28, 29 ), is also associated with increased low-frequency BPV in other forms of chronic hypertension (30). The combination of increased BPV and RAS activity observed in in utero programming of hypertension could account for the excess cardiovascular morbidity observed in adults with low birth weight, despite the relatively mild increase in blood pressure reported in this population (4).

Alteration of arterial baroreflex control of HR. The arterial baroreflex is critical in the development of hypertension. In- 

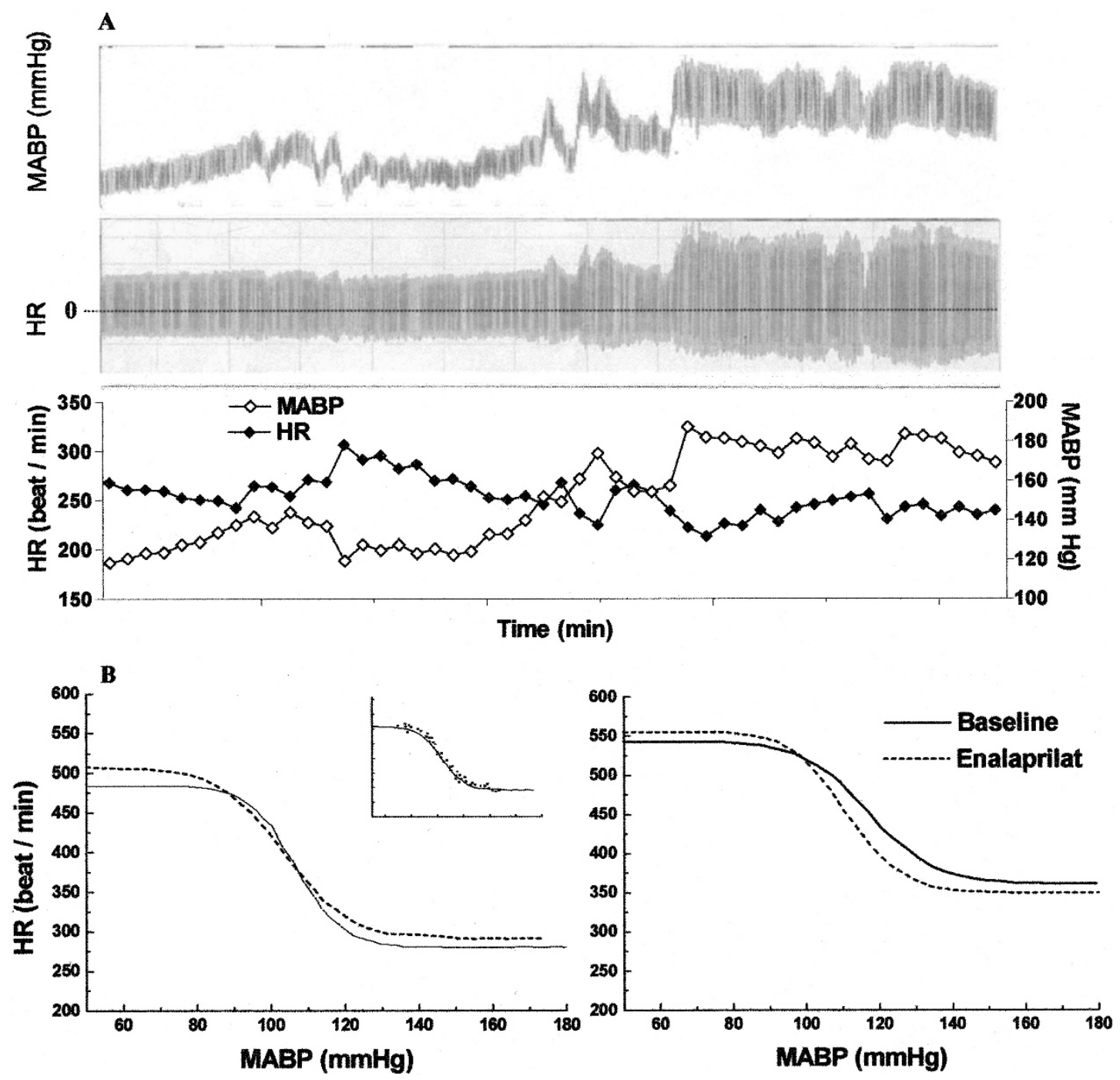

Figure 3. (A) Representative segment of a recording of blood pressure (top) and HR signal (middle) response to phenylephrine infusion. (Middle) The frequency at which the signal crosses the "0" line correlates with the HR (bpm); i.e. as HR slows with the increase in blood pressure, the amplitude of the signal increases as more time elapses between two beats. (Bottom) Data from the top two panels transposed as MABP $(\diamond)$ and HR $(\diamond)$ as a function of time. $(B)$ Representative illustration of the effects of maternal diets containing 18\% (control; left) and 9\% (right) protein on arterial baroreflex control of HR of the 9- to 12-wk-old offspring, before (baseline) and after i.v. enalaprilat. An example of the number of points used to generate the baroreflex curve is presented as an inset on the left graph. HR baroreflex response curve of $9 \%$ offspring is shifted toward higher pressures; after ACE-I, HR arterial baroreflex curve is reset toward lower pressure in $9 \%$ and not modified in $18 \%$ (see Table 1).
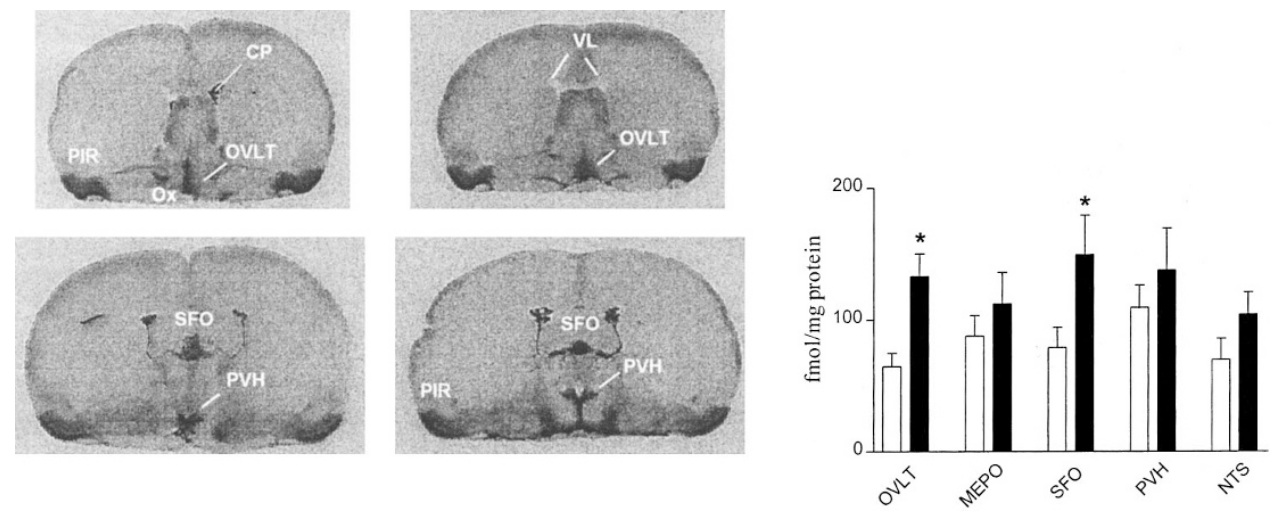

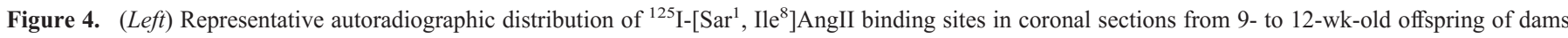
fed diets containing 18\% (control; left) and 9\% (right) protein during gestation. Note higher binding intensity in SFO and OVLT of $9 \%$ brain. Compiled losartan-sensitive binding in the different brain areas analyzed are presented on the right $(18 \%, \square ; 9 \%, \mathbf{\square})$. PIR, piriform cortex; PVH, paraventricular nucleus hypothalamus; Ox, optic chiasma; VL, lateral ventricle; CP, choroid plexus. Data are means \pm SEM; $n=7$ for each group. ${ }^{*} p<0.05 v s 18 \%$. 
trauterine growth restricted animals and humans, as well as hypertensive adult animals that were deprived during fetal life, show evidence of increased blood pressure along with a paradoxic normal or even slightly increased HR $(12,13)$. This observation was verified in the current study with the absence of a difference in resting HR between the two groups despite the higher MABP in the $9 \%$ offspring, suggesting an alteration in the arterial baroreflex. The latter is confirmed by the shift of the arterial baroreflex curve toward a higher pressure in the $9 \%$ offspring. As enalaprilat does not cross the blood-brain barrier (31), the effects observed after systemic administration of this ACE-I represent the role of peripherally derived AngII on cardiovascular function. Studies in mature animals have shown that circulating AngII alters baroreflex control of HR primarily by shifting the baroreflex curve to a higher blood pressure without modulating the gain $(32,33)$. Conversely, systemic administration of ACE-I or $\mathrm{AT}_{1}$ blocker decreases the blood pressure of hypertensive individuals without changing the sensitivity of the HR baroreflex curve (34). As baroreflex is not completely reset to control group values after ACE-I, this indicates that AngII is not the sole factor involved in modulating baroreflex control of HR in $9 \%$ animals. Changes in the relationship between arterial pressure and heart rate can result from changes in the baroreceptor itself and/or within the CNS. Baroreceptor endings are located in the walls of the carotid arteries and the aorta and sense the changes in blood pressure through changes in their stretch. Accordingly, vascular compliance, which can be decreased in individuals with low birth weight $(28,29)$, is an important determinant of the activity of the baroreceptors (35). Also, whether membrane characteristics of baroreceptor endings and changes in ion channels function within the baroreceptor membrane are altered by antenatal diet exposure is unknown (36). Centrally, changes in neurohormones that influence baroreflex efferent autonomic pathway as well as activation of other neural reflex pathways are potential factors that may be modified in fetal programming of high blood pressure and have an impact on arterial baroreflex (36).

The mechanism by which circulating AngII is implicated in HR baroreflex resetting is nonetheless dependent on the CNS. Indeed, circulating AngII does not influence carotid and aortic baroreceptor firing (33) (afferent loop) but can bind to $\mathrm{AT}_{1}$ receptors expressed by some brain circumventricular organs (e.g. AP, OVLT, SFO) $(37,38)$, which in turn modulate the efferent branch of the arterial baroreflex (39). We observed that blockade of central AngII by losartan in 9\% offspring decreases blood pressure without significantly altering arterial baroreflex control of HR, although there was a tendency for the curve to be reset to lower pressure. Losartan can cross the blood-brain barrier (37), but the dose administered centrally in our studies is $\sim 100$ times lower than a peripherally effective dose; we therefore consider that the effect of ICV losartan on arterial pressure reflects solely central blockade of $\mathrm{AT}_{1}$ receptors. Consequently, these data indicate that brain AngII participates in maintaining in utero programmed hypertension. Such a role for brain RAS has been shown in other forms of chronic hypertension such as renovascular hypertension (40) and chronic stress-induced hypertension (41). Endogenous brain AngII can elevate blood pressure through increases in efferent sympathetic activity, release of vasopressin from the hypothalamus, and synaptic inhibition of the baroreflex at the level of the nucleus tractus solitarius $(42,43)$.

Expression of AngII AT1 receptor in brain. Our findings of significant increased expression of the AngII $\mathrm{AT}_{1}$ receptor in specific brain areas involved in cardiovascular regulation further support a role for central AngII in the hypertension of 9\% offspring rats. The brain structures that are involved in cardiovascular modulation by AngII and that express the $\mathrm{AT}_{1}$ receptor are located in the forebrain (OVLT, MEPO, SFO, and PVH) and in the lower brainstem (NTS, AP, dorsal motor nucleus of the vagus, and nucleus ambiguus) (14). In the current studies, $\mathrm{AT}_{1}$ binding sites were detected in all of these areas, and binding intensity was found to be more strong in $9 \%$ offspring, markedly more so in the OVLT and the SFO. Both circulating and central AngII can activate $\mathrm{AT}_{1}$ receptors from the SFO and OVLT $(44,45)$. AngII microinjected into the SFO causes a pressor effect that is mediated by vasopressin release and increased sympathetic activity $(46,15)$. Elevated brain AngII binding sites have also been reported in spontaneously hypertensive fetal and newborn rats $(47,48)$, and blockade of central RAS in adult spontaneously hypertensive rat can reverse their chronic hypertension (49). The underlying mechanisms and regulatory processes that lead to increased $\mathrm{AT}_{1}$ receptor brain expression in $9 \%$ offspring are unknown but may involve a defect in nitric oxide pathway $(27,50,51)$, positive feedback regulation by elevated brain AngII $(52,53)$, and glucocorticoids $(12,54,55)$.

\section{REFERENCES}

1. Law CM, Shiell AW 1996 Is blood pressure inversely related to birth weight? The strength of evidence from a systematic review of the literature. J Hypertens 14:935941

2. Camussi A, Bianchi G 1988 Genetics of essential hypertension. From the unimodalbimodal controversy to molecular technology. Hypertension 12:620-628

3. Beilin LJ 1990 Diet and lifestyle in hypertension: changing perspectives. J Cardiovasc Pharmacol 16:62-66

4. Barker DJP 1994 Mothers, Babies and Disease in Later Life. BMJ Publishing Group London

5. Langley-Evans SC, Gardner DG, Jackson AA 1996 Association of disproportionate growth of fetal rats in late gestation with raised systolic blood pressure in later life. J Reprod Fertil 106:307-312

6. Woodall SM, Johnston BM, Breier BH, Gluckman PD 1996 Chronic maternal undernutrition in the rat leads to delayed postnatal growth and elevated blood pressure of offspring. Pediatr Res 40:438-443

7. Langley-Evans SC, Jackson AA 1995 Captopril normalises systolic blood pressure in rats with hypertension induced by fetal exposure to maternal low protein diets. Comp Biochem Physiol A Physiol 110:223-228

8. Sherman RC, Langley-Evans SC 2000 Antihypertensive treatment in early postnatal life modulates prenatal dietary influences upon blood pressure in the rat. Clin Sci (Lond) 98:269-275

9. Kingdom JP, McQueen J, Connell JM, Whittle MJ 1993 Fetal angiotensin II levels and vascular (type I) angiotensin receptors in pregnancies complicated by intrauterine growth retardation. Br J Obstet Gynaecol 100:476-482

10. Kingdom JC, Hayes M, McQueen J, Howatson AG, Lindop GB 1999 Intrauterine growth restriction is associated with persistent juxtamedullary expression of renin in the fetal kidney. Kidney Int 55:424-429

11. Su DF, Miao CY 2002 Arterial baroreflex function in conscious rats. Acta Pharmacol Sin 23:673-679

12. Langley-Evans SC 1997 Maternal carbenoxolone treatment lowers birthweight and induces hypertension in the offspring of rats fed a protein-replete diet. Clin Sci (Lond) 93:423-429

13. Murotsuki J, Challis JR, Han VK, Fraher LJ, Gagnon R 1997 Chronic fetal placental embolization and hypoxemia cause hypertension and myocardial hypertrophy in fetal sheep. Am J Physiol 272:R201-R207

14. Lenkei Z, Palkovits M, Corvol P, Llorens-Cortès C 1997 Expression of angiotensin type-1 (AT1) and type-2 (AT2) receptor mRNAs in the adult rat brain: a functional neuroanatomical review. Front Neuroendocrinol 18:383-439

15. Wright JW, Harding JW 1995 Brain angiotensin receptor subtypes AT1, AT2, and AT4 and their functions. Regul Pept 59:269-295 
16. Paxinos G, Watson C 1986 The Rat Brain in Stereotaxic Coordinates, 2nd Ed. Academic Press, Sydney

17. Nafz B, Wagner CD, Persson PB 1997 Endogenous nitric oxide buffers blood pressure variability between 0.2 and $0.6 \mathrm{~Hz}$ in the conscious rat. Am J Physiol 272:H632-H637

18. Kent BB, Drane JW, Blumenstein B, Manning JW 1972 A mathematical model to assess changes in the baroreceptor reflex. Cardiology 57:295-310

19. Curhan GC, Willett WC, Rimm EB, Spiegelman D, Ascherio AL, Stampfer MJ 1996 Birth weight and adult hypertension, diabetes mellitus, and obesity in US men. Circulation 94:3246-3250

20. Koupilova I, Leon DA, Lithell HO, Berglund L 1997 Size at birth and hypertension in longitudinally followed 50-70-year-old men. Blood Press 6:223-228

21. Poulter NR, Chang CL, MacGregor AJ, Snieder H, Spector D 1999 Association between birth weight and adult blood pressure in twins: historical cohort study. BMJ 319:1330-1333

22. Stein CE, Fall CH, Kumaran K, Osmond C, Cox V, Barker DJP 1996 Fetal growth and coronary heart disease in south India. Lancet 348:1269-1273

23. Langley-Evans SC 2000 Critical differences between two low protein diet protocols in the programming of hypertension in the rat. Int J Food Sci Nutr 51:11-17

24. Lurbe E, Torro I, Rodriguez C, Alvarez V, Redon J 2001 Birth weight influences blood pressure values and variability in children and adolescents. Hypertension 38:389-393

25. Su D-F, Miao C-Y 2001 Blood pressure variability and organ damage. Clin Exp Pharmacol Physiol 28:709-715

26. Stauss HM, Nafz B, Mrowka R, Persson PB 2000 Blood pressure control in eNOS knock-out mice: comparison with other species under NO blockade. Acta Physiol Scand 168:155-160

27. Lamireau D, Nuyt AM, Hou X, Bernier S, Beauchamp M, Gobeil F Jr, Lahaie I, Varma DR, Chemtob S 2002 Altered vascular function in fetal programming of hypertension. Stroke 33:2992-2998

28. Martin H, Hu J, Gennser G, Norman M 2000 Impaired endothelial function and increased carotid stiffness in 9-year-old children with low birthweight. Circulation 102:2739-2744

29. Martyn CN, Barker DJ, Jespersen S, Greenwald S, Osmond C, Berry C 1995 Growth in utero, adult blood pressure, and arterial compliance. Br Heart J 73:116-121

30. Dabire H, Lacolley P, Chaouche-Teyara K, Fournier B, Safar ME 2002 Relationship between arterial distensibility and low-frequency power spectrum of blood pressure in spontaneously hypertensive rats. J Cardiovasc Pharmacol 39:98-106

31. Jouquey S, Mathieu M-N, Hamon G, Chevillard C 1995 Effect of chronic treatment with trandolapril or enalapril on brain ACE activity in spontaneously hypertensive rats. Neuropharmacology 34:1689-1692

32. Brooks VL 1995 Chronic infusion of angiotensin II resets baroreflex control of heart rate by an arterial pressure-independent mechanism. Hypertension 26:420-424

33. Guo GB, Abboud FM 1984 Angiotensin II attenuates baroreflex control of heart rate and sympathetic activity. Am J Physiol 246:H80-H89

34. Vesalainen RK, Kantola IM, Airaksinen KE, Tahvanainen KU, Kaila TJ 1998 Vaga cardiac activity in essential hypertension: the effects of metoprolol and ramipril. Am J Hypertens 11:649-658

35. Lanfranchi PA, Somers VK 2002 Arterial baroreflex function and cardiovascular variability: interactions and implications. Am J Physiol 283:R815-R826

36. Chapleau MW, Hajduczok G, Abboud FM 1988 Mechanisms of resetting of arteria baroreceptors: an overview. Am J Med Sci 295:327-334
37. Li Z, Bains JS, Ferguson AV 1993 Functional evidence that the angiotensin antagonist losartan crosses the blood-brain barrier in the rat. Brain Res Bull 30:33-39

38. Song K, Allen AM, Paxinos G, Mendelsohn FAO 1992 Mapping of angiotensin II receptor subtype heterogeneity in rat brain. J Comp Neurol 316:467-484

39. Bishop VS, Sanderford MG 2000 Angiotensin II modulation of the arterial baroreflex Role of the area postrema. Clin Exp Pharmacol Physiol 27:428-431

40. Faber JE, Brody MJ 1984 Central nervous system action of angiotensin during onset of renal hypertension in awake rats. Am J Physiol 247:H349-H360

41. Qian ZM, Xiao DS, Huang WQ, Tang PL, Xu B 1997 Central Ang II receptor involved in carotid sinus reflex resetting in chronically stressed rats. Physiol Behav 62:241-247

42. Head GA, Mayorov DN 2001 Central angiotensin and baroreceptor control of circulation. Ann N Y Acad Sci 940:361-379

43. Matsumura K, Averill DB, Ferrario CM 1998 Angiotensin II acts at AT1 receptors in the nucleus of the solitary tract to attenuate the baroreceptor reflex. Am J Physio 275:R1611-R1619

44. Mangiapane ML, Simpson JB 1980 Subfornical organ lesions reduce the pressor effect of systemic angiotensin II. Neuroendocrinology 31:380-384

45. Van Houten M, Mangiapane ML, Reid IA, Ganong WF 1983 [Sar,Ala]angiotensin II in cerebrospinal fluid blocks the binding of blood-borne [125I]angiotensin II to the circumventricular organs. Neuroscience 10:1421-1426

46. Mangiapane ML, Brody MJ 1986 Mechanisms of hemodynamic responses to electrical stimulation of subfornical organ. Am J Physiol 250:R1117-R1122

47. Cook VI, Grove KL, Speth RC, McMenamin KM, Harding JW 1993 Differences between perinatal angiotensin binding in the brains of SHR and WKY rats. Regul Pept 45:395-405

48. Raizada MK, Lu D, Tang W, Kurian P, Summers C 1993 Increased angiotensin II type-1 receptor gene expression in neuronal cultures from spontaneously hypertensive rats. Endocrinology 132:1715-1722

49. Wu JN, Berecek KH 1993 Prevention of genetic hypertension by early treatment of spontaneously hypertensive rats with the angiotensin converting enzyme inhibitor captopril. Hypertension 22:139-146

50. Kadekaro M, Summy-Long JY 2000 Centrally produced nitric oxide and the regulation of body fluid and blood pressure homeostasis. Clin Exp Pharmacol Physiol 27:450-459

51. Nakata T, Takeda K, Harada S, Oguni A, Hatta T, Kawa T, Itoh H, Sasaki S, Nakagawa M 2001 Role of the central nervous system in the development of hypertension produced by chronic nitric oxide blockade in rats. Hypertens Res 24:39-45

52. Porter JP 1999 Chronic intracerebroventricular infusion of angiotensin II increases brain AT1 receptor expression in young rats. Brain Res Dev Brain Res 112:293-295

53. Jo H, Yang EK, Lee WJ, Park KY, Kim HJ, Park JS 1996 Gene expression of central and peripheral renin-angiotensin system components upon dietary sodium intake in rats. Regul Pept 67:115-121

54. Aguilera G, Kiss A, Luo X 1995 Increased expression of type 1 angiotensin I receptors in the hypothalamic paraventricular nucleus following stress and glucocorticoid administration. J Neuroendocrinol 7:775-783

55. Dodic M, Abouantoun T, O'Connor A, Wintour EM, Moritz KM 2002 Programming effects of short prenatal exposure to dexamethasone in sheep. Hypertension 40:729734 